\title{
Short-Term Postharvest Carbon Dioxide Treatments Induce Selective Molecular and Metabolic Changes in Grape Berries
}

\author{
Elisa Becatti, ${ }^{\dagger, \|}$ Lamia Chkaiban, ${ }^{*}, \|$ Pietro Tonutti, ${ }^{*}$ Claudio Forcato, $\$$ \\ Claudio Bonghi, ${ }^{\S}$ and Anna Maria Ranieri* ${ }^{*} \uparrow$ \\ ${ }^{\dagger}$ Dipartimento di Biologia delle Piante Agrarie, University of Pisa, via del Borghetto 80, I-56124 Pisa, Italy, \\ *Scuola Superiore Sant’Anna, Piazza Martiri della Libertà 33, I-56127 Pisa, Italy, and ${ }^{\S}$ Dipartimento di \\ Agronomia Ambientale e Produzioni Vegetali, University of Padova, Viale dell'Università 16, \\ I- 35020 Legnaro (Padova), Italy. "These authors contributed equally to this work.
}

\begin{abstract}
Detached wine grapes (Vitis vinifera cv. 'Trebbiano', white skinned) were treated for 3 days with $30 \mathrm{kPa}$ of $\mathrm{CO}_{2}$ and then transferred to air for an additional 9 days to partially dehydrate (about $20 \%$ weight loss). At the end of the $\mathrm{CO}_{2}$ treatment on withering berries, total polyphenols and flavonoids were maintained in the skin, but to a more limited extent in the pulp. An induction of the proanthocyanidin synthesis appeared to be one of the responses to the treatment because both $(+)$-catechin and (-)-epicatechin concentrations increased in the skin. The skin and pulp of the grape berries showed different molecular responses to a high $\mathrm{CO}_{2}$ treatment. As revealed by microarray hybridizations, 217 and 75 genes appeared differentially expressed in the skin and pulp of treated samples, respectively. Functional categorization and gene enrichment analyses pointed out that epicarp cells undergo more pronounced changes in transcript profiling at the end of the incubation period. Highly represented categories in both tissues were related to protein, stress, transcript, RNA, and hormone (ethylene, ABA) metabolism. Fermentation, $\mathrm{CHO}$ metabolism, and redox regulation functional categories were represented only in the skin.
\end{abstract}

KEYWORDS: Fruit ripening; gene expression; microarray; polyphenols; postharvest elicitors; proanthocyanidins; transcriptome; Vitis vinifera

\section{INTRODUCTION}

Alterations in the concentrations of $\mathrm{O}_{2}$ and $\mathrm{CO}_{2}$ may prolong the storage life of some horticultural produce through a reduction in respiration and other metabolic reactions and a decrease in decay. Although there is much in the literature on the application and effects of controlled atmosphere storage (1), where $\mathrm{CO}_{2}$ levels are generally set at around $2-5 \mathrm{kPa}$, information on the responses to elevated ( $20 \mathrm{kPa}$ or higher) $\mathrm{CO}_{2}$ concentrations remains limited (2). These concentrations can be used during the storage of tolerant commodities or for short-term treatments aimed at delaying softening, as reported for peaches and strawberries $(3-6)$. Elevated $\mathrm{CO}_{2}$-induced stresses affect the general metabolism of produce with beneficial or detrimental effects on composition and quality depending on gas concentrations (and the interaction with other gases such as oxygen and ethylene), treatment duration, and genotype, even within the same species. Different responses to such treatments have been reported in Fragaria spp., where cultivars showing different tolerances to elevated $\mathrm{CO}_{2}$ are present (7). Short-term high- $\mathrm{CO}_{2}$ treatments have also been used as postharvest elicitors to induce the synthesis of phytochemicals and/or beneficial changes in composition affecting quality traits such as deastringency in persimmons $(8,9)$. In tomato fruit $(10)$, high concentrations of $\mathrm{CO}_{2}$ are effective in blocking the mRNA

*Corresponding author [phone +39 (0)50 2216605; fax +39 (0)50 2216630; e-mail aranieri@agr.unipi.it]. accumulation of genes involved in ripening-related changes. In addition, they are effective in altering the expression of other genes with a role in different metabolic processes as shown using a heterologous microarray approach in two strawberry cultivars (11). If maintaining firmness and delaying ripening are common characteristics in response to $\mathrm{CO}_{2}$, an important difference may exist in terms of antioxidant activity and polyphenol metabolism $(12,13)$. As a general effect, an altered metabolism/stability of anthocyanins and other phenolics, such as phenolic acids and flavonols, has been observed in strawberries stored under $\mathrm{CO}_{2}$-enriched atmospheres (13). Specific changes in the polyphenol metabolism have also been detected in table grapes, where elevated $\mathrm{CO}_{2}$ concentrations were effective in maintaining berry quality and reducing fungal decay during storage at $0{ }^{\circ} \mathrm{C}(14)$.

A modulation in the expression pattern of specific phenylpropanoid genes (phenylalanine ammonia-lyase, PAL; chalcone synthase, CHS) and in the accumulation of different phenol compounds, in particular a reduction in the total anthocyanins and trans-resveratrol, have been observed in 'Cardinal' table grapes following treatments with $20 \mathrm{kPa}$ of $\mathrm{CO}_{2}(14-16)$. The limited induction of stilbene synthase (STS) gene expression suggests that the reduction in fungal decay observed in treated grapes is not mediated by the activation of the stilbene pathway (14).

Phenol compounds are also of paramount importance for wine grapes including those used for the production of dessert and 
fortified wines, which are often made with berries that are partially dehydrated after detachment. During the postharvest dehydration process, which may last from a few weeks to several months, grapes undergo metabolic changes affecting the volatiles and phenol compounds of the berries and, as a consequence, of the resulting wines $(17-19)$. Bellincontro et al. (20) reported that, in 'Aleatico' grapes, the total phenols and total anthocyanins decreased during the first 12 days of postharvest dehydration, whereas an increase in the resveratrol content was observed in 'Corvina' grapes at the end of a long withering process (17). Using a molecular approach, Zamboni et al. (21) showed that during postharvest dehydration, the flavonoid biosynthetic pathway is activated concurrently with an induction of the genes involved in the oxidation/polymerization of phenolic compounds. The general metabolism and the composition of the berries could be partly modulated and the loss of produce due to decay reduced when the withering process is carried out under a strict control of relative humidity, temperature, and ventilation. This occurs in dehydration chambers or tunnels $(18,22)$, where treatments with specific gaseous elicitors can also be performed.

In this paper we report the effects on transcriptome and phenol compound concentration of a short-term postharvest $\mathrm{CO}_{2}$ treatment on 'Trebbiano' grapes (white-skinned) at the end of the incubation period and during the time course of a limited dehydration process.

\section{MATERIALS AND METHODS}

Chemicals. All of the reagents were of analytical and HPLC grade. Methanol, ethanol, $n$-butanol, ethyl acetate, $\mathrm{HCl}$, phenol, chloroform, isoamyl alcohol, gallic acid, (+)-cathechin, (-)-epicatechin, caffeic acid, quercitin, cyanidin, proanthocyanidin B1, proanthocyanidin B2, DMACA reagent, Folin-Ciocalteu reagent, iron(II) sulfate, sodium hydroxide, sodium nitrite, aluminum chloride, sodium carbonate, sodium acetate, sodium perchlorate, PVPP, PEG, SDS, mercaptoethanol, isopropanol, EDTA, and lithium chloride were purchased from Sigma-Aldrich (Milan, Italy). RQ1 RNase-Free DNase was bought from Promega, (Madison, WI) and RNAguard (RNase inhibitor) from Amersham Biosciences (Piscataway, NJ). Gaseous $\mathrm{CO}_{2}$ and gaseous and liquid $\mathrm{N}_{2}$ were bought from SOL spa (Pisa, Italy). Water used as HPLC mobile phase and for analytical reactions was Milli-Q (Millipore, Bedford, MA) purified water. C18 and tC18 Sep-Pak Plus cartridges were from Waters SpA (Milano, Italy). Minisart $0.45 \mu \mathrm{m}$ filters were purchased from Prokeme (Firenze, Italy).

Plant Material and Treatments. Vitis vinifera L. cv. 'Trebbiano' grapes were harvested at technological maturity stage $\left(20.8^{\circ}\right.$ Brix), and berries were separated from the bunches, selected on the basis of similar size and color, and incubated in small Plexiglas boxes at $20^{\circ} \mathrm{C}$. Berries were maintained under a continuous flow $(100 \mathrm{~mL} / \mathrm{min})$ of air or gas mixture ( $21 \mathrm{kPa}$ of $\mathrm{O}_{2}, 49 \mathrm{kPa}$ of $\mathrm{N}_{2}, 30 \mathrm{kPa}$ of $\mathrm{CO}_{2}$ ) for 3 days. At the end of the 3 day treatment period, boxes were opened and both control and treated berries were allowed to dehydrate for a further 9 days at $20^{\circ} \mathrm{C}$. At harvest (T0), day 3 (end of the treatment), day $9(3+6)$, and day $12(3+9)$ berries were frozen separately in liquid $\mathrm{N}_{2}$ for skin and pulp and stored at $-80^{\circ} \mathrm{C}$.

Extraction of Polyphenols. Skin and flesh samples $(0.5 \mathrm{~g})$ were ground with liquid $\mathrm{N}_{2}$. The plant material was extracted on a magnetic stirrer three times using a total of $90 \mathrm{~mL}$ of methanol/water $(80: 20, \mathrm{v} / \mathrm{v})$. The liquid extract was separated by centrifugation $(14000 \mathrm{~g}, 15 \mathrm{~min})$ at $4{ }^{\circ} \mathrm{C}$. The final volume was quantified, and the extract, reduced to $16 \mathrm{~mL}$ by rotavapor, was filtered with a $0.45 \mu \mathrm{m}$ filter Minisart, divided into two aliquots of $8 \mathrm{~mL}$, and stored at $-80^{\circ} \mathrm{C}$.

Phenol Compound Quantification. Total phenols were determined using the Folin-Ciocalteu method, modified as described by Barbolan et al. (23). Amounts of $1.85 \mathrm{~mL}$ of distilled water, $0.125 \mathrm{~mL}$ of FolinCiocalteu reagent, and $0.5 \mathrm{~mL}$ of a $20 \%$ sodium carbonate solution were added to $25 \mu \mathrm{L}$ of liquid extract sample in a test tube, making a final volume of $2.5 \mathrm{~mL}$. The solution was homogenized and left to stand for $30 \mathrm{~min}$, and the absorbance was determined at $750 \mathrm{~nm}$. The total phenols were calculated as milligrams of gallic acid equivalents. Total flavonoids were determined as described by Kim et al. (24). Amounts of $60 \mu \mathrm{L}$ of $5 \%$
$\mathrm{NaNO}_{2}, 40 \mu \mathrm{L}$ of $10 \% \mathrm{AlCl}_{3}$, and $400 \mu \mathrm{L}$ of $1 \mathrm{M} \mathrm{NaOH}$ were added to $100 \mu \mathrm{L}$ of liquid extract. The solution was diluted with $200 \mu \mathrm{L}$ of distilled water and mixed, and the absorbance was determined at $510 \mathrm{~nm}$. The flavonoid amount was calculated as milligrams of catechin equivalents. Tartaric acid ester and flavonol contents were determined using a method described by Romani et al. (25). An aliquot of $25 \mu \mathrm{L}$ of sample extract was diluted with $225 \mu \mathrm{L}$ of $10 \%$ ethanol and $250 \mu \mathrm{L}$ of $0.1 \% \mathrm{HCl}$ in $95 \%$ ethanol, and $1 \mathrm{~mL}$ of $2 \% \mathrm{HCl}$ was then added. The solution was mixed, and the absorbances were determined at $320 \mathrm{~nm}$ for tartaric acid esters and at $360 \mathrm{~nm}$ for flavonols. Tartaric acid ester and flavonol amounts were calculated as milligrams of caffeic acid and quercetin, respectively. Total flavan-3-ols were determined with $p$-(dimethylamino)cinnamaldehyde (DMACA) reagent, as described by Nigel and Glories (26). An amount of $10 \mu \mathrm{L}$ of the sample extract was diluted with $90 \mu \mathrm{L}$ of methanol. Next, $250 \mu \mathrm{L}$ of $\mathrm{HCl}(0.24 \mathrm{~N}$ in $\mathrm{MeOH}), 250 \mu \mathrm{L}$ of DMACA solution $(0.2 \%$ in $\mathrm{MeOH}$ ), and $250 \mu \mathrm{L}$ of methanol were added. The absorbance was determined at $640 \mathrm{~nm}$, and the total amount of flavan-3-ols was calculated as milligrams of catechin equivalents. Condensed tannins, or proanthocyanidins, were determined in accordance with the method described by Waterman and Mole (27). Butanol reagent was prepared by mixing $128 \mathrm{mg}$ of $\mathrm{FeSO}_{4} \cdot 7 \mathrm{H}_{2} \mathrm{O}$ with $5 \mathrm{~mL}$ of concentrated $\mathrm{HCl}$ and brought to $100 \mathrm{~mL}$ with $n$-butanol. An aliquot of $50 \mu \mathrm{L}$ of extract sample was mixed with $700 \mu \mathrm{L}$ of butanol reagent and heated at $95^{\circ} \mathrm{C}$ in a water bath for $45 \mathrm{~min}$. The sample was cooled, $250 \mu \mathrm{L}$ of $n$-butanol was added, and the absorbance was measured at $550 \mathrm{~nm}$. The total amount of condensed tannin was calculated as milligrams of cyanidin equivalents. The assays were performed by using an Ultro spec 2100 pro UV-visible spectrophotometer (Amersham Biosciences).

Proanthocyanidin Fractionation. The method described by Sun et al. (28) was used to obtain the proanthocyanidin (PA) fractionation in monomeric (fraction 1), oligomeric PA (fraction 2), and polymeric PA (fraction 3). Sample extracts $(8 \mathrm{~mL}$ ) were adjusted to $\mathrm{pH} 7.0$ with $\mathrm{NaOH}$ solution. Samples were loaded onto two Sep-Pak cartridges that were connected in series, that is, the upper one was a $\mathrm{tC}_{18}$ Sep-Pak and the lower one was a $\mathrm{C}_{18}$ Sep-Pak. The cartridges were preconditioned with $10 \mathrm{~mL}$ of methanol, $10 \mathrm{~mL}$ of ethyl acetate, and $10 \mathrm{~mL}$ of water ( $\mathrm{pH} 7.0)$. After loading the samples, the cartridges were rinsed with $10 \mathrm{~mL}$ of water $(\mathrm{pH} 7.0)$ to eliminate phenolic acids and then dried with gaseous $\mathrm{N}_{2}$. Elutions were carried out first with $25 \mathrm{~mL}$ of ethyl acetate to elute fractions 1 and 2 $(\mathrm{F} 1+\mathrm{F} 2)$ and then with $10 \mathrm{~mL}$ of methanol to elute fraction $3(\mathrm{~F} 3)$. For the separation of monomeric from oligomeric $\mathrm{PA}, \mathrm{F} 1+\mathrm{F} 2$ was evaporated to dryness under vacuum at $25^{\circ} \mathrm{C}$, dissolved in distilled water ( $\mathrm{pH} 7.0$ ), and then loaded onto the same connected cartridges preconditioned with distilled water ( $\mathrm{pH}$ 7.0). The cartridges were then dried with $\mathrm{N}_{2}$, and $\mathrm{F} 1$ was eluted with $25 \mathrm{~mL}$ of diethyl ether and F2 with $10 \mathrm{~mL}$ of methanol. The three fractions, brought to dryness with arotary evaporator and suspended into $500 \mu \mathrm{L}$ of methanol, were ready for HPLC analyses.

HPLC Analyses. HPLC analyses were performed to evaluate the composition of fractions 1 (F1) and 2 (F2) obtained from the fractionation of proanthocyanidins. The analytical separation of fractionated proanthocyanidins was performed by a Spectra System P4000 HPLC, equipped with a UV 6000 LP photodiode array detector (Thermo Fisher Scientific, Waltham, MA). The column $(250 \times 4.60 \mathrm{~mm}, 5 \mu \mathrm{m})$ was a Phenomenex Prodigy LC-18 RP. The mobile phase flow rate was fixed at $1.0 \mathrm{~mL} / \mathrm{min}$. For the gradient elution of $\mathrm{F} 1 \mathrm{H}_{2} \mathrm{O}$, pH 2.7 (with formic acid) (A), and methanol (B) were used like mobile phases: $0 \mathrm{~min}, 90 \% \mathrm{~A}, 10 \% \mathrm{~B} ; 5 \mathrm{~min}$, $90 \%$ A, $10 \%$ B; $20 \mathrm{~min}, 70 \%$ A, 30\% B; $28 \mathrm{~min}, 10 \%$ A, $90 \%$ B; $35 \mathrm{~min}$, $90 \% \mathrm{~A}, 10 \% \mathrm{~B}$. For the gradient elution of $\mathrm{F} 2, \mathrm{H}_{2} \mathrm{O}(\mathrm{A})$ and $10 \%$ acetic acid (B) were used: 0 min, $90 \%$ A, $10 \%$ B; 15 min, $40 \%$ A, 60\% B; $35 \mathrm{~min}$, $15 \% \mathrm{~A}, 85 \% \mathrm{~B} ; 50 \mathrm{~min}, 0 \% \mathrm{~A}, 100 \% \mathrm{~B}$. The detection was at $280 \mathrm{~nm}$, and the column temperature was maintained at $30{ }^{\circ} \mathrm{C}$ using a Phenomenex ThermaSphere TS-130 HPLC column temperature controller (Phenomenex srl, Castel Maggiore, Italy). Identification and quantification were carried out using UV spectra, peak retention times, and peak areas from calibration curves established using external standards $((+)$-catechin, $(-)$ epicatechin, proanthocyanidins B1 and B2) according to the method of Gonzàlez-Manzano et al. (29). Retention times were 19.09 and $24.36 \mathrm{~min}$ for (+)-catechin and (-)-epicatechin and 21.11 and $33.99 \mathrm{~min}$ for proanthocyanidins B1 and B2, respectively (Supporting Information, Figure S1).

RNA Extraction. RNA was extracted from the pulp and skin using the perchlorate method described by Rizzini et al. (22). Three grams of 
Table 1. Specific Primers for Vitis vinifera Used for Semiquantitative PCR Analyses

\begin{tabular}{|c|c|c|c|c|}
\hline name & sequence $5^{\prime} \rightarrow 3^{\prime}$ & $\begin{array}{l}\text { length of the } \\
\text { PCR product }\end{array}$ & $\begin{array}{c}\text { relative positions } \\
\text { of primers }\end{array}$ & $\begin{array}{l}\text { reference } \\
\text { sequence }\end{array}$ \\
\hline F cis-epoxycarotenoid dioxygenase & 5'-GGC TCT TTC TCT TTC CAT AGG CCC ACC-3' & 229 & 251 & TC57089 \\
\hline R cis-epoxycarotenoid dioxygenase & $5^{\prime}-\mathrm{CCA}$ ACG CGG TCT CCA CGG CAT CC--3' & & 479 & \\
\hline F alcohol dehydrogenase 2 & 5'-GAA GTG GAA GTG GCG CCT CCA CAG G-3 & 213 & 129 & TC69306 \\
\hline $\mathrm{R}$ alcohol dehydrogenase 2 & $5^{\prime}$-GGT GAA TAC AGG AAG AAC ATG GTC TCC AGG-3' & & 341 & \\
\hline F endopolygalacturonase & 5'-AAG CCC TTC AAA TCC GCC ATT GAC C-3' & 248 & 223 & TC64309 \\
\hline R endopolygalacturonase & $5^{\prime}$-CCA AAA ATA AGG CTA CTA TGC CTT CCA CC-3' & & 470 & \\
\hline F heatshock protein & $5^{\prime}$-TGA GCG ATT ACG ATG ATG ATG AGC GTC G-3' & 199 & 652 & TC63472 \\
\hline $\mathrm{R}$ heatshock protein & $5^{\prime}$-TTT CAC GTC TCA TGA TCG CCC AAT TCC-3' & & 454 & \\
\hline
\end{tabular}

frozen tissue was ground to a fine powder in liquid $\mathrm{N}_{2}$. Twenty milliliters of extraction buffer composed of $5 \mathrm{M}$ sodium perchlorate, $0.3 \mathrm{M}$ Tris $\mathrm{HCl}$, $\mathrm{pH} 8.3$, PVPP $8.5 \% \mathrm{p} / \mathrm{v}$, PEG $2 \% \mathrm{p} / \mathrm{v}$, SDS $1 \% \mathrm{p} / \mathrm{v}$, and $\beta$-mercaptoethanol $1 \% \mathrm{v} / \mathrm{v}$ was added to the frozen powder. The mixture was stirred at room temperature for $60 \mathrm{~min}$. The homogenate was then filtered using Whatman no. 4 filter paper and Whatman GF/B glass filters. The eluate was mixed with 0.8 volume of isopropanol and left for at least $60 \mathrm{~min}$ at $-20{ }^{\circ} \mathrm{C}$. Nucleic acids were pelleted by centrifugation for $20 \mathrm{~min}$ at $5400 \mathrm{~g}$. The resulting pellet was washed with $70 \%(\mathrm{v} / \mathrm{v})$ ethanol and resuspended in $1 \mathrm{~mL}$ of TE buffer (10 mM Tris-HCl, $\mathrm{pH} 7.6,0.1 \mathrm{mM}$ EDTA). This solution was then sequentially extracted with $1 \mathrm{~mL}$ of phenol $(\mathrm{pH} 8.0$, equilibrated with Tris-HCl, room temperature), $1 \mathrm{~mL}$ of phenol/chloroform/ isoamyl alcohol $(25: 24: 1, \mathrm{v} / \mathrm{v} / \mathrm{v})$, and $1 \mathrm{~mL}$ of chloroform/isoamyl alcohol $(24: 1, \mathrm{v} / \mathrm{v})$. The RNA was precipitated by adding 0.1 volume of $3 \mathrm{M}$ sodium acetate, $\mathrm{pH}$ 5.2, and 0.6 volume of isopropanol, then centrifuged, rinsed, dried, and resuspended in $600 \mu \mathrm{L}$ of DEPC water. RNA was precipitated overnight by adding $300 \mu \mathrm{L}$ of $4 \times$ TBE and $300 \mu \mathrm{L}$ of $8 \mathrm{M}$ $\mathrm{LiCl}$. Precipitated RNA was collected, rinsed, then dried, and resuspended in $100 \mu \mathrm{L}$ of DEPC water. All RNA samples were treated with RQ1 RNase-Free DNase and RNAguard (RNase inhibitor) for $30 \mathrm{~min}$, followed by phenol-chloroform extraction and isopropanol precipitation. The quality of RNA was verified by intact ribosomal bands that were observed when run on agarose gel electrophoresis and by absorbance ratios $(A 260 / 280)$ ranging from 1.8 to 2.0 .

Microarray Hybridizations, Target Annotation, and Functional Analysis. Microarray experiments were conducted using the grape AROS V1.0 platform (http://www.operon.com). Grape AROS V1.0 is a set of 14562 oligonucleotide probes (70mers), obtained from The Institute for Genomic Research (TIGR) Grape Gene Index (VvGI), release 3 (http:// www.tigr.org/tdb/tgi/vvgi/index.html), described in detail by Da Silva et al. (30). The 14562 oligos, harboring a $5^{\prime}$ amino linker, were spotted twice onto each glass slide at CRIBI laboratories (University of Padova, Italy), as described by Trainotti et al. (31). Total RNA was converted into target cDNA by reverse transcription using the SuperScript Indirect cDNA Labeling System (Invitrogen, Carlsbad, CA) following the manufacturer's instructions. Microarray analysis was performed by comparing control and $\mathrm{CO}_{2}$-treated berries (separately for skin and pulp) sampled at the end of the 3 day treatment. Three slides (six technical replicates) were hybridized. Microarray prehybridizations, hybridizations, washing, and data analyses were performed according to the methods of Ziliotto et al. (32). Normalized split data were loaded in MeV 3.1 and, for each comparison, a $66 \%$ cutoff was imposed to select genes differentially expressed by 1-plus unpaired SAM (significance analysis of microarrays (33)) analysis. Probes with significant changes in expression (threshold ratio expressed as $\log _{2}$, higher than 0.8 and lower than -0.8 for up- and down-regulation, respectively) were identified at $\Delta$ values giving a $0 \%$ false discovery rate.

Functional analysis was performed on the MapMan platform by using a mapping file specifically developed for the microarray based on the Grape AROS V1.0 in which were mapped 14452 oligos of 14562 (34). Gene enrichment analyses were performed to statistically determine the more significant BINs present in the differentially expressed (DE) gene set for pulp and skin. Contingency tables were created for each BIN annotated in the DE gene set, and the Fisher exact test was applied. $P$ values of $<0.1$ were considered to determine the statistically significant categories (confidence level of 0.90 ). All analyses were performed with Perl scripts and R software environment.
Gene Expression Analyses. Semiquantitative PCR analysis was carried out according to the manufacturer's instruction (Reverse Transcription System, Promega, Madison, WI). A pair of primers was designed for each of the analyzed genes (Table 1). A Quantum 18S RNA Universal kit was used as housekeeping. The cycle conditions were adapted for each gene following the Quantum 18S RNA Universal kit (Ambion Inc.) instructions. The PCR products were separated by electrophoresis on $1.5 \%$ agarose gels. The amplication mix was prepared using GoTaq protocol (Promega). The amplification products were scanned and quantified using Quantity One software (Bio-Rad, Hercules, CA). Each cDNA sample was run in triplicate. The relative expression level for each target gene was determined as band intensity relative to the housekeeping gene (transcript ratio).

Statistical Analyses. Values reported in figures are the means of three replications at each sampling time. The effect of $\mathrm{CO}_{2}$ treatment was evaluated by one-way ANOVA. The significance level was set at $P=0.05$ and performed by Tukey-Kramer's test. For microarray statistical analyses significance analysis of microarrays (SAM) was used (33).

\section{RESULTS}

Phenol Compounds. The postharvest weight loss was not significantly different between control and treated berries that lost about $6,16.5$, and $20 \%$ of fresh weight at days 3,9 , and 12 , respectively. The polyphenol compound concentrations were more abundant in the skin than in the pulp (Figure 1). Compared with the samples at harvest (T0), total polyphenols, flavonoids, flavonols, and tartaric acid esters decreased from day 3 and throughout the experimental period in the skins of the control berries (Figure 1a,c,e,g). At the end of the 3 day treatment, $\mathrm{CO}_{2}$ resulted in the maintenance of total polyphenol and flavonoid concentrations (Figures 1a,c) but not of flavonols and tartaric acid esters (Figure 1e,g). Compared with nontreated berries, $\mathrm{CO}_{2}$ treatment increased the skin concentration of flavonols and tartaric acid esters at day $3+6$ (Figure 1e,g) and of total phenols and flavonoids at day $3+9$ (Figure 1a,c). The effect of $\mathrm{CO}_{2}$ treatment of total polyphenols in the skin was not observed in the pulp (Figure 1b). No significant differences among pulp samples were observed in terms of flavonoids, flavonols, and tartaric acid ester concentration at the end of the 3 day treatment and the subsequent sampling dates (Figure 1d,f,h).

Total flavan-3-ols (monomers, oligomers PA, and polymeric PA) and condensed tannins (oligomers PA and polymeric PA) in control berry skins declined throughout the experimental period (Figure 2a,b). At the end of the $\mathrm{CO}_{2}$ treatment, the concentration of flavan-3-ols was similar to that detected in the T0 samples, but then decreased to a level comparable to the control samples (Figure 2a). In treated berries, condensed tannin concentrations were similar to the controls, but then they increased at the end of the considered period (Figure $\mathbf{2 b}$ ). Unlike the control samples, a marked increase in both $(+)$-catechin and (-)-epicatechin concentrations was detected at the end of the $\mathrm{CO}_{2}$ treatment followed 

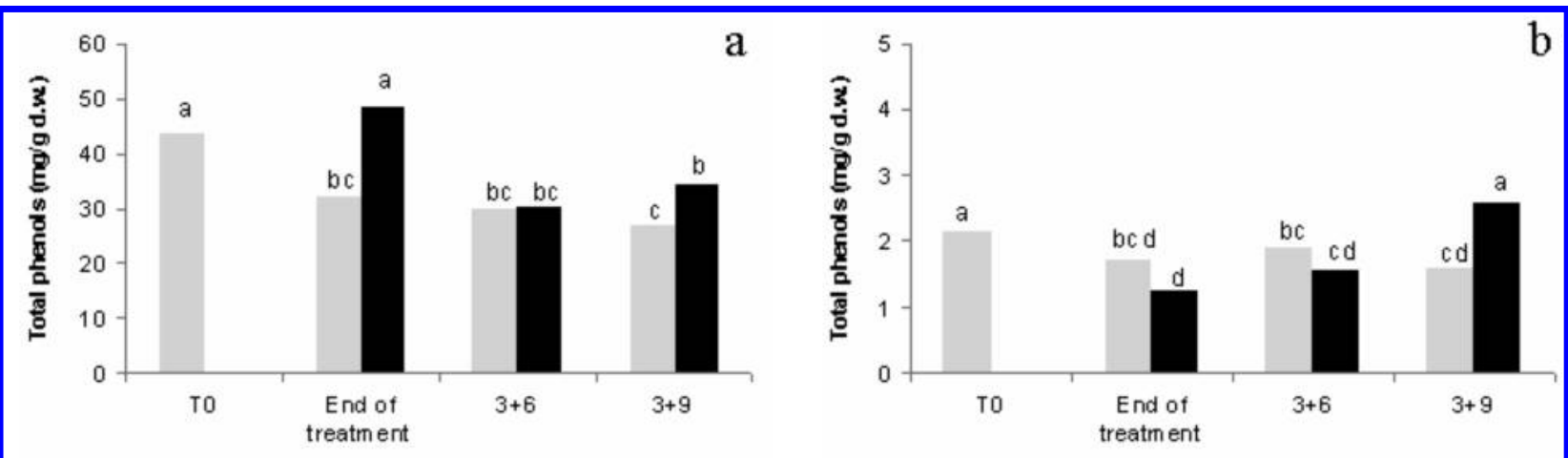

Sa mpling time (days)

Sa mpling time (days)
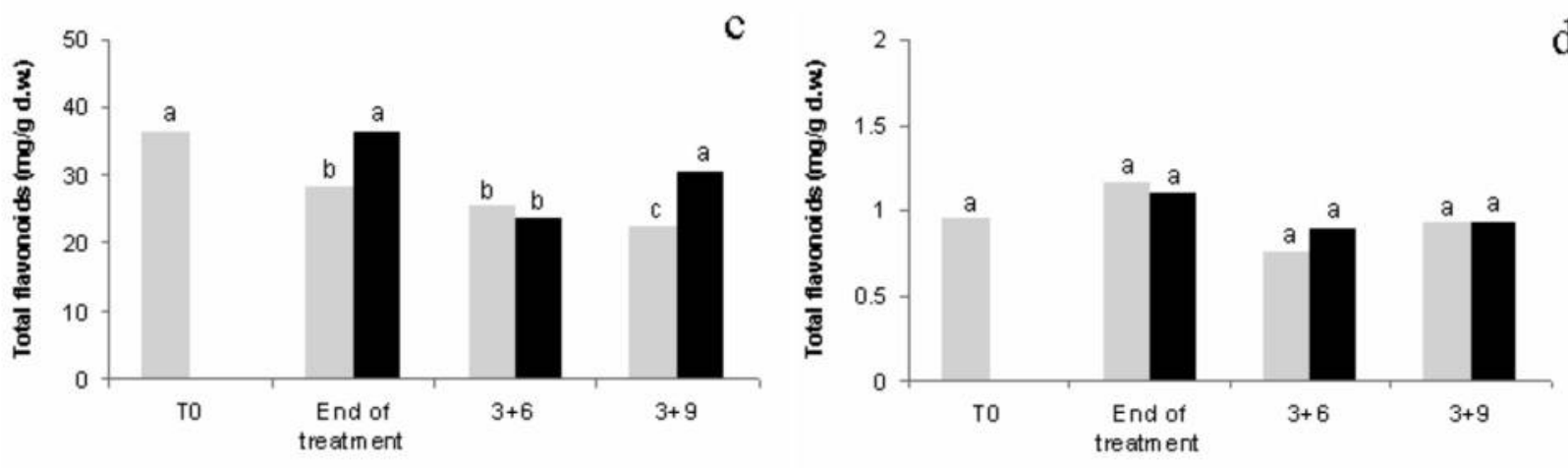

d

Sampling time (days)

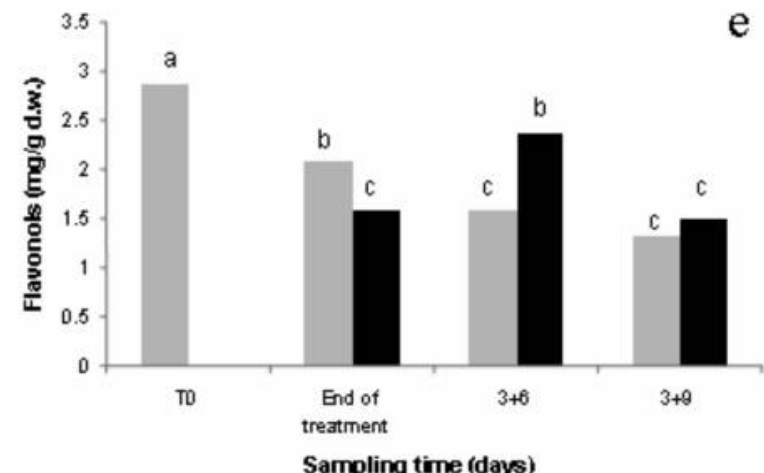

e

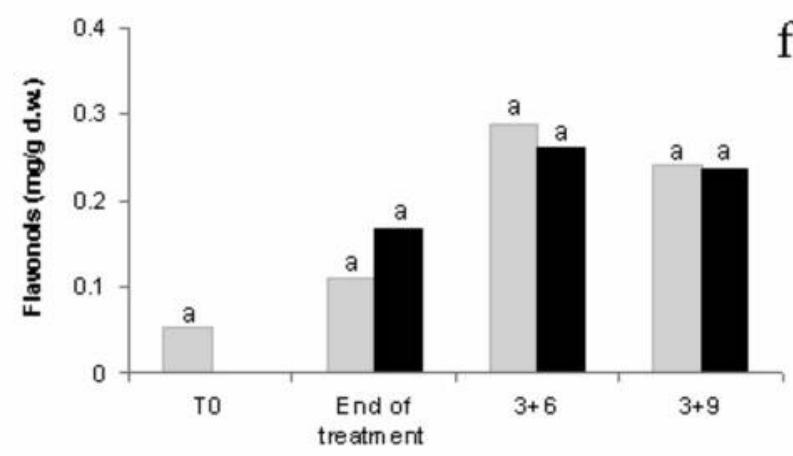

f

Sampling time (days)
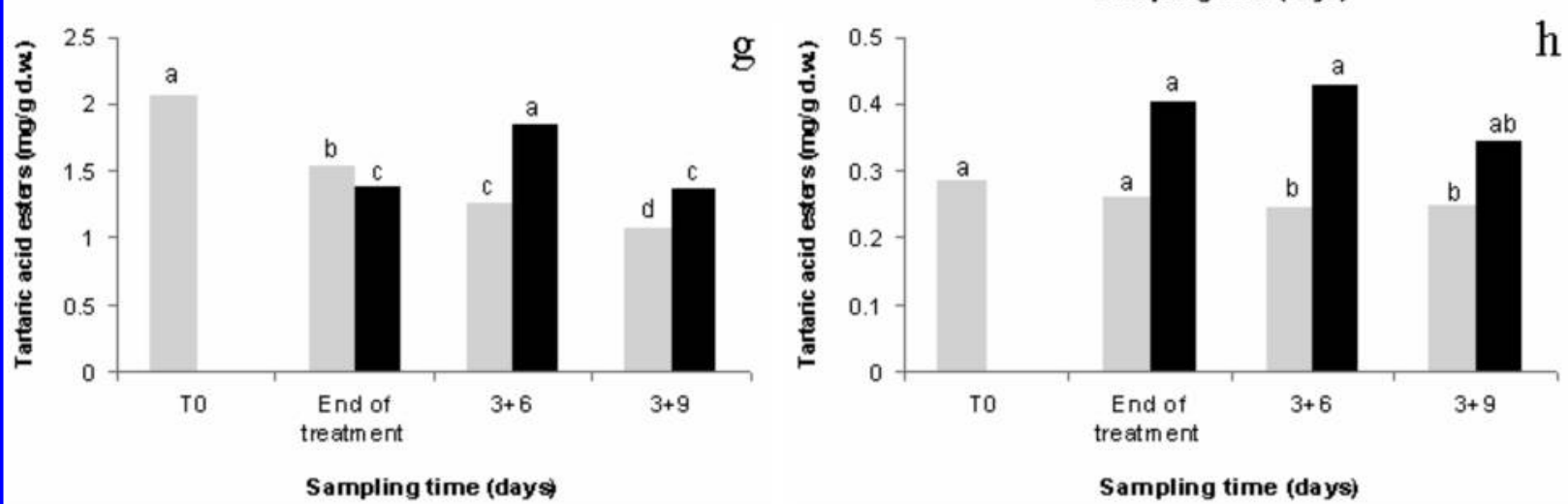

Control

Treated

Figure 1. Total phenols (a, b), flavonoids (c, d), flavonols (e, f), and tartaric acid esters ( $\mathbf{g}, \mathbf{h})$ concentrations (mg/g of dry weight) measured, respectively, in skin and flesh of 'Trebbiano' berries sampled at harvest (T0), at the end of the 3 day incubation period (end of treatment), and after 6 and 9 days of dehydration. For each sampling time different letters indicate statistically significant differences according to the Tukey-Kramer test $(P=0.05)$. Data represent the mean of three measurements. 


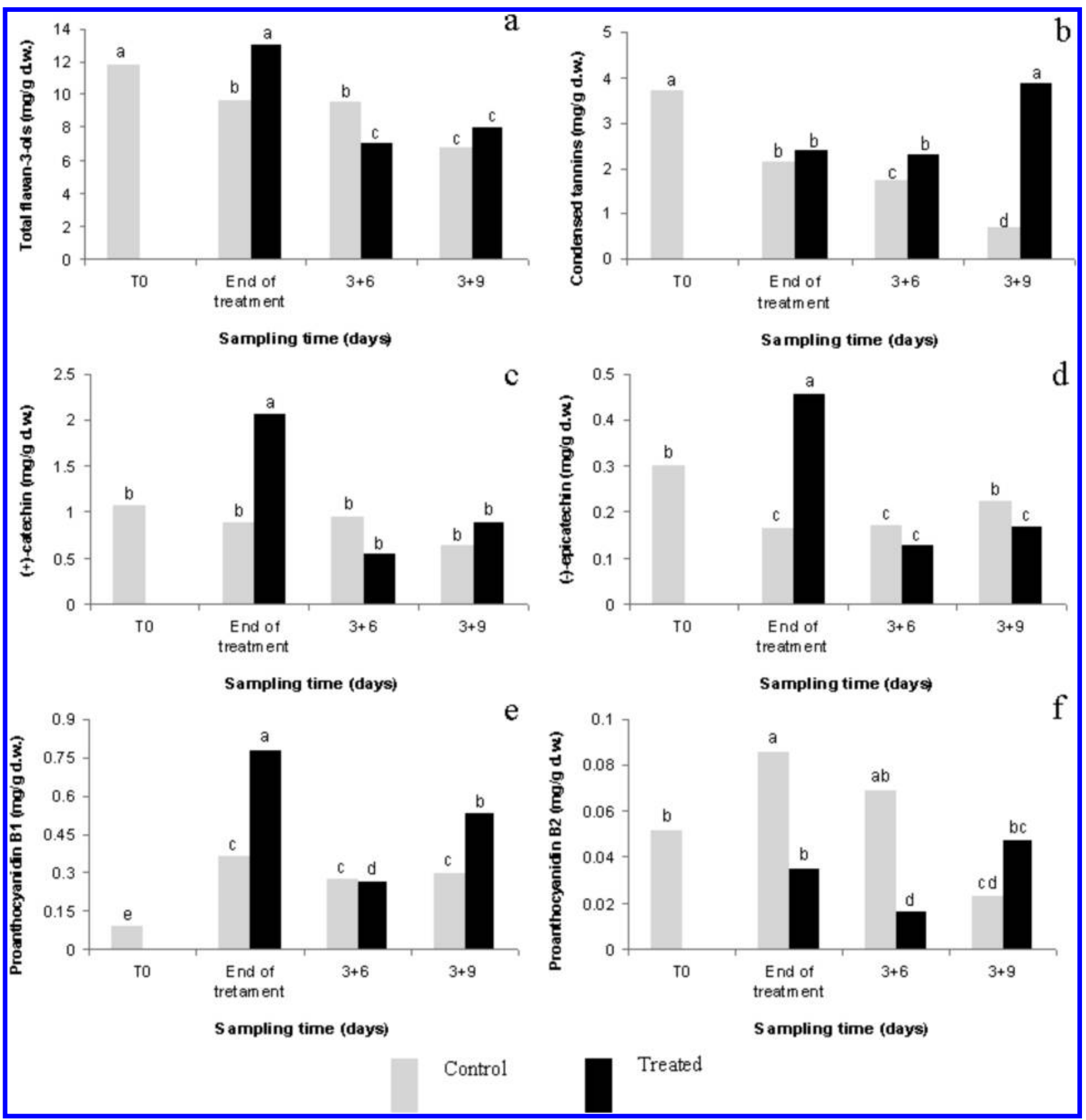

Figure 2. Flavan-3-ols (a), condensed tannins (b), (+)-catechin (c), (-)-epicatechin (d), proanthocyanidin B1 (e), proanthocyanidin B2 (f) concentration ( $\mathrm{mg} / \mathrm{g}$ dry weight) in the skin of 'Trebbiano' berries sampled at harvest (T0), at the end of the 3 day incubation period (end of treatment), and after 6 and 9 days of dehydration. For each sampling time different letters indicate statistically significant differences between means according to the Tukey-Kramer test $(P=0.05)$. Data represent the mean of three measurements.

by a significant decrease thereafter (Figure 2c,d). Similarly, proanthocyanidin B1 concentration was significantly higher in treated samples at the end of the incubation period and, to a lesser extent at day 3+9 (Figure 2e). Proanthocyanidin B2, less abundant than proanthocyanidin B1, increased after 3 days in control samples (Figure 2f), whereas a reduced concentration was observed in treated berries at days 3 and $3+6$ (Figure 2f).

Transcript Profiling. To better describe, at molecular level, the effects of the short-term high- $\mathrm{CO}_{2}$ treatment on the general metabolism of 'Trebbiano' grape berries, microarray (Grape AROS V1.0) hybridizations were performed and transcript profiles of controls and $\mathrm{CO}_{2}$-treated berries (sampled at day 3, end of treatment) compared. Totals of 217 and 75 probes were differentially expressed in skin and pulp, respectively. In skins, only 16 genes appeared to be up-regulated, whereas 201 were down-regulated.
In the pulp, 30 genes were induced, whereas 45 were repressed by the $\mathrm{CO}_{2}$ treatment (Supporting Information, Tables S1 and S2). To corroborate the microarray experiments, semiquantitative PCR analyses of four genes (heat-shock protein (HSP, Vv_10003682) and endopolygalacturonase (PG, Vv_10006744) for pulp; alcohol dehydrogenase (ADH, Vv_10010766) and 9-cis-epoxycarotenoid dioxygenase (NCED, $\mathrm{V}_{\mathrm{V}}{ }_{1}$ 10009127) for skin) were performed. The results confirmed the microarray hybridizations (Figure 3).

All significant probes (skin and pulp) were mapped on the functional categories (called BIN), and their distribution, not considering those categorized in the BIN 35 (not assigned genes, 126 for the skin and 36 for the pulp), is reported in Figure 4. BINs related to protein (BIN 29), transport (BIN 34), hormone metabolism (BIN 17), RNA (BIN 27), and stress (BIN 20) were highly represented in both skin and pulp tissues. BIN 13 (amino acid 


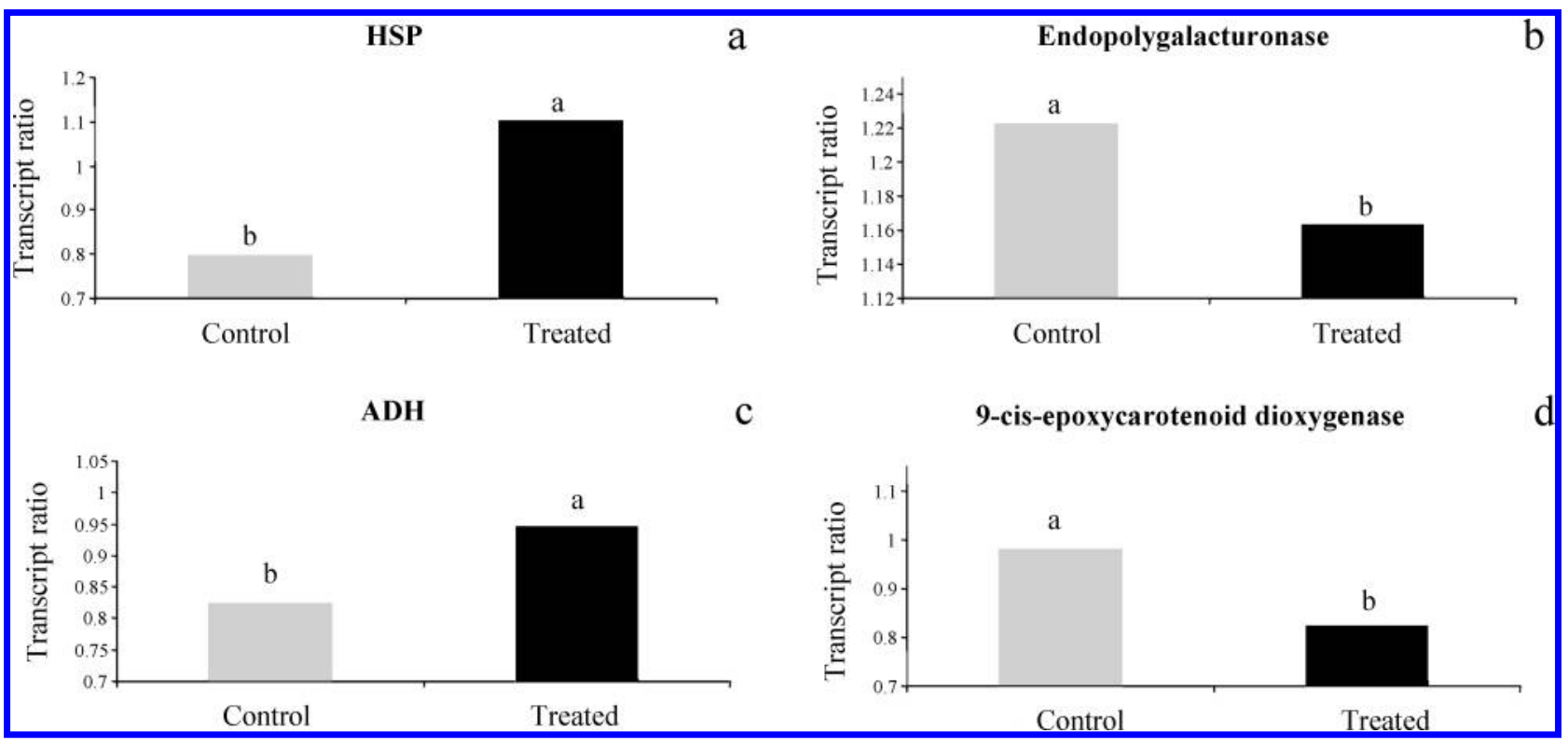

Figure 3. Semiquantitative PCR analyses of heat-shock protein (Vv_10003682) (a) and endopolygalacturonase (Vv_10006744) (b) genes in pulp and alcohol dehydrogenase (Vv_10010766) (c) and 9-cis-epoxycarotenoid dioxygenase (Vv_10009127) (d) genes in skin of control and $\mathrm{CO}_{2}$-treated berries sampled at the end of the 3 day incubation period. Data are means \pm SE of three semiquantitative RT-PCR experiments.

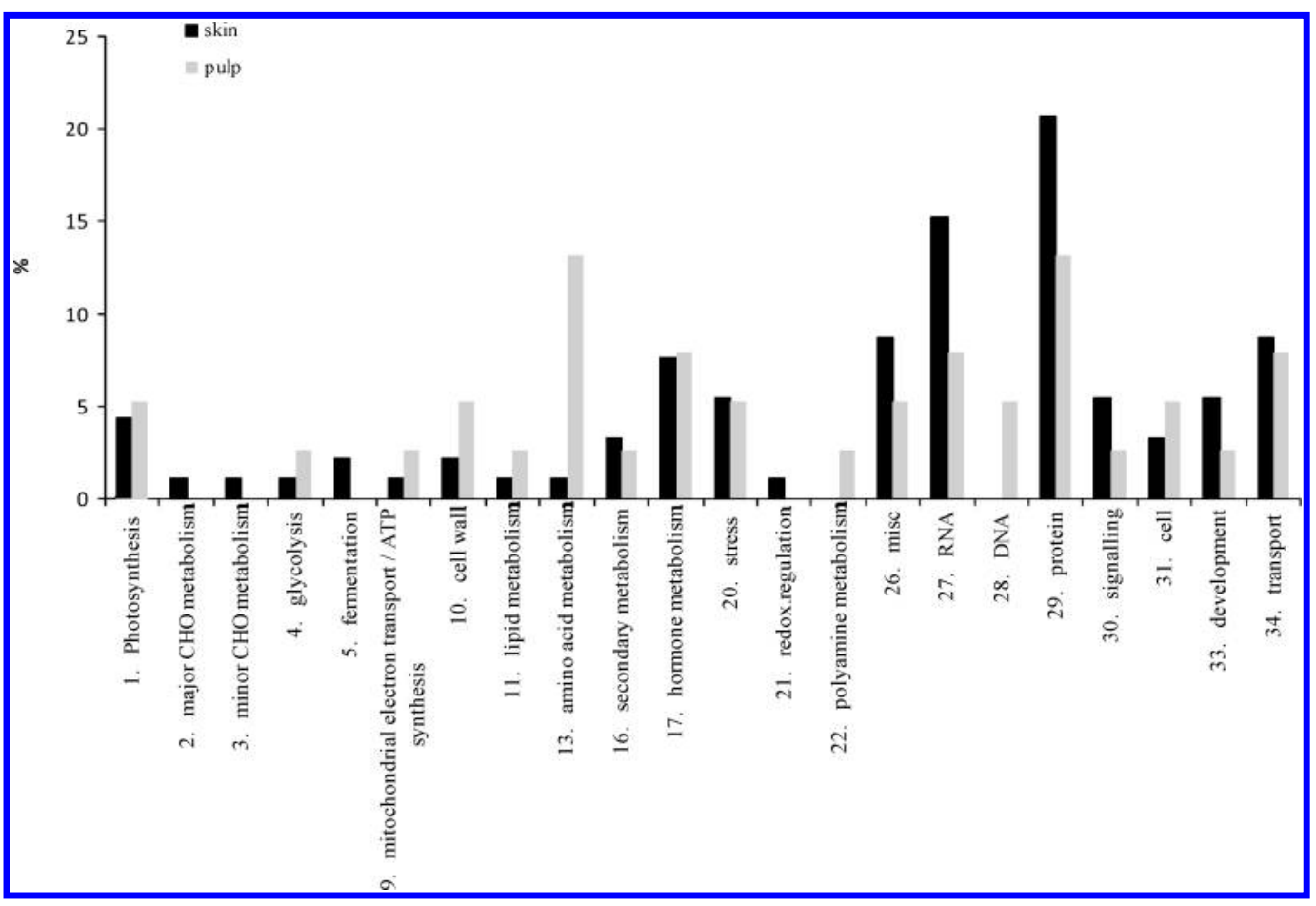

Figure 4. Distribution of differentially expressed (DE) genes in skin (black bars) and pulp (gray bars) in the functional categories (BINs) present in the MapMan platform. Number of genes for each BIN is expressed as percentage of total DE gene separately for flesh and skin. Genes categorized in the BIN 35 (not assigned) were not considered.

metabolism) was also highly represented in pulp that, differently from skin, appeared to be in particular affected by the treatment in terms of DNA (BIN 28) and polyamine metabolism (BIN 22) gene expression. A differential expression of genes involved in major (BIN 2) and minor (BIN 3) CHO metabolism, fermentation (BIN 5), and redox regulation (BIN 21) was observed only in skin (Figure 4). A gene enrichment analysis was carried out to identify BIN and sub-BINs significantly more affected by $\mathrm{CO}_{2}$ in both tissues (Supporting Information, Tables S3 and S4). A more detailed analysis allowed the identification, in the different BINs and sub-BINs, of genes involved in specific processes. In the
sub-BIN 17.5 (hormone metabolism, ethylene) two genes, a 1-aminocyclopropane-1-carboxylate oxidase (ACO, Vv_100004370) and an ethylene-forming enzyme-like (Vv_10010132), both responsible for the conversion of ACC to ethylene, appeared to be induced in the skin and pulp, respectively. Considering ethylene and polyamine biosynthetic pathways, an $S$-adenosylmethionine synthetase (AdoMet, Vv_10000146), belonging to sub-BIN13.1, and an $S$-adenosyl-L-methionine decarboxylase (Vv_10000476), belonging to sub-BIN 22.1.2, were down-regulated in the pulp. In skins, a NCED (Vv_10009127, sub-BIN 17.1.1.1.10) gene that catalyzes the first step of ABA biosynthesis from carotenoids in chloroplasts 
was repressed (Figure 3). A significant over-representation was observed for sub-BINs belonging to BIN 10 (cell wall). In skin, a gene enrichment was observed in the sub-BIN 10.8.99 that includes a pectin methyl esterase (PME, Vv_10006937). Together with the expression data of PG (Figure 3), this would indicate that major changes occur in cell wall pectin metabolism of treated berries.

The BIN 5 (fermentation) showed significant gene enrichment in skin. In this BIN a down-regulated aldehyde dehydrogenase (Vv_10002953) and one ADH (Vv_10010766) showing an upregulation (Figure 3) in response to the treatment are present. Considering BIN 20 (stress), one HSP binding (Vv_10001645) was repressed in skin, whereas a HSP (Vv_10003682) appeared to be induced (Figure 3) and an osmotin-like protein ( $\mathrm{VV}_{\mathrm{V}}$ 10010885) was down-regulated in the pulp at the end of the 3 day $\mathrm{CO}_{2}$ treatment.

\section{DISCUSSION}

High $\mathrm{CO}_{2}$ levels can be applied for short periods of time as a pretreatment or as intermittent exposures to induce metabolic responses which, in general, affect ripening-associated changes and disease development. In tomato fruit exposed to $20 \mathrm{kPa}$ of $\mathrm{CO}_{2}$ concentration for 3 days, the inhibition of ripening is due to the suppression of ripening-associated gene expression as a result of the stress effect exerted by the treatment (10). The presence of an altered metabolism induced in fruit by short exposure to high $\mathrm{CO}_{2}$ concentrations has been shown for 'Trebbiano' grape berries as indicated by the number of genes (292) differentially expressed at the end of the 3 day treatment. Using a heterologous transcriptomic approach, Ponce-Valadez et al. (11) found that the most highly represented genes that were differentially expressed in strawberries treated with $20 \mathrm{kPa}$ of $\mathrm{CO}_{2}$ were involved in protein and nucleic acid metabolism. We similarly observed in $\mathrm{CO}_{2^{-}}$ treated grape berries a high representation of BINs 27 (RNA) and 29 (protein) in both skin and pulp and BIN 13 (amino acid metabolism) in pulp. The different number of genes affected by the treatment in the skin (217) and pulp (75) clearly highlights the marked difference between the two tissues in terms of reactivity to external stimuli. In fact, according to the putative function and gene enrichment analyses (Figure $\mathbf{4}$ and Tables S3 and S4 of the Supporting Information), epicarp cells appear to undergo more pronounced changes in transcriptome profiling when $\mathrm{CO}_{2}$ levels are increased during storage. This reflects the specialization and the specific functional role of mesocarp and epicarp within the berry, in particular under stress conditions as demonstrated, at a molecular level, by Grimplet et al. (35), who reported different tissue-specific mRNA expression patterns of an extensive repertoire of genes in watered and water-deficit stressed grape berries.

Among the physiological changes occurring in detached fruit stored under altered atmospheric compositions, those affecting hormone biosynthesis and action are of paramount importance considering the role played by hormones in different developmental stages including ripening and senescence. In climacteric fruit, such as tomato and peach $(10,5)$, exposure to high $\mathrm{CO}_{2}$ levels is effective in blocking or reducing the expression of 1-aminocyclopropane-1-carboxylic acid synthase (ACS) and ACO, responsible for the last steps of ethylene synthesis. Although grape berries are classified as nonclimacteric, modulation of the gene expression involved in the ethylene production pathway (AdoMet, ACO) by high $\mathrm{CO}_{2}$ could indicate that ethylene is involved in the high- $\mathrm{CO}_{2}$ stress-responsive mechanisms of mature $V$. vinifera fruit. The hypothesis that $\mathrm{CO}_{2}$ may have an effect on ethylene action in nonclimacteric fruit was formulated by Ponce-Valadez et al. (11), who found, in two strawberry cultivars, a down-regulation of three ethylene receptors following a $48 \mathrm{~h}$ treatment with $20 \mathrm{kPa}$ of $\mathrm{CO}_{2}$. Whether the different transcriptional behaviors of ACO genes following exposure to high $\mathrm{CO}_{2}$ (down-regulated in climacteric fruit $(5,10)$, up-regulated in the grape berry) reflects differences in ACO family/gene structure, regulatory elements, and organization in climacteric and nonclimacteric fruit remains to be elucidated. It is interesting to note that the $\mathrm{CO}_{2}$ treatment induced a strong inhibitory effect on proteolitic enzyme RING-type genes (Vv_10001370 and Vv_10007350 in Table S1 of the Supporting Information) involved in protein turnover regulating ethylene biosynthesis and response (36). According to microarray experiments, also ABA, involved in the hormonal control of grape berry ripening (37), appeared to be affected by exposure to high $\mathrm{CO}_{2}$. Biochemical and genetic studies have demonstrated that NCED is the key enzyme in the ABA biosynthetic pathway in plants where the hormone is derived from $\mathrm{C}_{40}$-cis-epoxycarotenoids, either $9^{\prime}$-cis-neoxanthin or $9^{\prime}$-cis-violaxanthin or both, which are cleaved by the NCED to produce xanthoxin, the direct $\mathrm{C}_{15}$ precursor of ABA (38) The down-regulation of NCED suggests that a reduced synthesis of the hormone occurs in $\mathrm{CO}_{2}$-treated berries as detected in ripe peaches, where treatment with $100 \% \mathrm{CO}_{2}$ for $48 \mathrm{~h}$ resulted in a marked decrease in ABA content paralleled by a reduction in 9-Z-violaxantin (6). An altered expression pattern of NCED together with the differential transcript accumulation of aldehyde dehydrogenase and $\mathrm{ADH}$ genes caused by a $\mathrm{CO}_{2}$ treatment might also result in a modified berry aromatic profile. NCED expression data and the hypothesis of a reduced ABA synthesis are consistent with previous results indicating that high $\mathrm{CO}_{2}$ levels may delay the ripening and senescence and extend postharvest life of grape berries (14). In our study this delay is indirectly confirmed by the PME and PG down-regulation, two cell-wall enzymes induced at ripening and responsible for softening and changes in the physical parameters of the berry $(39,40)$. High $\mathrm{CO}_{2}$ treatments performed in harvested produce affect several secondary metabolism processes including the phenylpropanoid pathway (2). Elevated $\mathrm{CO}_{2}$ concentrations were effective in suppressing the biosynthesis and accumulation of anthocyanins in strawberries (13), pomegranate (41), and red-skinned grapes (16).

Besides anthocyanin synthesis, high $\mathrm{CO}_{2}$ concentrations reduce the trans-resveratrol content during the cold storage of table grapes $(14,15)$. Our data indicate that other phenylpropanoid metabolic processes appear to be affected by $\mathrm{CO}_{2}$ in 'Trebbiano' berries. In fact, maintenance of the same level detected in $\mathrm{T} 0$ samples of total phenol and flavonoid concentrations in the skin (Figure 1a,c) would seem to indicate that the degrading processes (e.g., oxidation) that occur in harvested berries undergoing dehydration and lead to a decrease in polyphenol content (20) are affected by $\mathrm{CO}_{2}$. Preliminary analyses indicate a reduction of polyphenol oxidase activity in $\mathrm{CO}_{2}$-treated berries as also observed in 'Kyoho' grapes (42). The marked increase in (+)catechin and (-)-epicatechin at the end of the 3 day treatment (Figure 2) suggests that the pathway leading to the formation of flavan-3-ols is activated in harvested berries during treatment with $\mathrm{CO}_{2}$. This activation, however, appears to be limited to the incubation period because significant decreases of flavan-3-ols have been detected in the post-treatment period. Of the different classes of phenolics, only anthocyanins (in red-skinned berries) accumulate throughout ripening, whereas the other phenolics exhibit accumulation patterns generally up to the veraison stage and then decline during ripening. This is the result of degradation and the use of other compounds in biosynthesis or conjugation with other components (43).

The increase of flavan-3-ols concentration detected in treated 'Trebbiano' grapes and the pattern of anthocyanin and transresveratrol concentrations in $\mathrm{CO}_{2}$-treated grape berries $(14-16)$ 
suggest that the monomeric flavan-3-ol biosynthetic pathway is under different control mechanism(s). Takos et al. (44) demonstrated that condensed tannin biosynthesis genes are regulated separately from other flavonoid biosynthesis genes in apple fruit skin, which might also be the case of grape berries. Expression analyses of genes involved in monomeric flavan-3-ol biosynthesis will help to confirm the hypothesis that this pathway is selectively affected by postharvest high- $\mathrm{CO}_{2}$ treatments. Flavan-3-ols, such as catechin and epicatechin, and oligomeric proanthocyanidins have inhibitory and antifungal properties toward different fungi including Botrytis cinerea (45). Thus, the observed efficacy of treatments with high $\mathrm{CO}_{2}$ in table grapes to control decay caused in particular by B. cinerea (46) could also be due to the enhanced synthesis of monomeric and oligomeric flavan-3-ols in the skin of $\mathrm{CO}_{2}$-treated berries. Considering that the potent nephrotoxin ochratoxin A, which is present in food and beverages including wine, is produced in harvested berries prior to the alcoholic fermentation (47) and that high $\mathrm{CO}_{2}$ was found to be effective in reducing the growth of different mycotoxigenic molds (48), it would be interesting to evaluate the effect of this treatment also in terms of the control of mycotoxin contamination in berries undergoing both limited or prolonged postharvest dehydration processes.

In conclusion, short-term high- $\mathrm{CO}_{2}$ treatment on harvested grape berries was effective in altering the general metabolism, in particular of skin tissues, as revealed by transcriptome profiling studies. With regard to specific secondary metabolism processes, the phenylpropanoid pathway appeared to be differentially affected with marked changes for proanthocyanidins in particular. Future research is needed to assess the possible application of this technique for table grape storage and the wine industry.

\section{ACKNOWLEDGMENT}

Special thanks to Federico Martinelli for technical assistance in performing semiquantitative PCR analyses and to Claudia Scattino for collaboration in phenol compound quantifications.

Supporting Information Available: HPLC chromatograms, lists of up- and down-regulated genes, and gene enrichment analyses in skin and pulp of $\mathrm{CO}_{2}$-treated berries. This material is available free of charge via the Internet at http://pubs.acs.org.

\section{LITERATURE CITED}

(1) Yahia, E. M. Modified and Controlled Atmospheres for the Storage. Transportation, and Packaging of Horticultural Commodities; CRC Press: Boca Raton, FL, 2009.

(2) Kanellis, A.; Tonutti, P.; Perata, P. Biochemical and molecular aspects of modified and controlled atmospheres. In Modified and Controlled Atmosphere for the Storage, Transportation, and Packaging of Horticultural Commodities; Yahia, E. M., Ed.; CRC Press: Boca Raton, FL, 2009; pp 553-567.

(3) Bonghi, C.; Ramina, A.; Ruperti, B.; Vidrih, R.; Tonutti, P. Peach fruit ripening and quality in relation to picking time, and hypoxic and high $\mathrm{CO}_{2}$ short-term postharvest treatments. Postharvest Biol. Technol. 1999, 16, 213-222.

(4) Harker, F. R.; Elgar, H. J.; Watkins, C. B.; Jackson, P. J.; Hallett, I. C. Physical and mechanical changes in strawberry fruit after high carbon dioxide treatments. Postharvest Biol. Technol. 2000, 19, 139-146.

(5) Mathooko, F. M.; Tsunashima, Y.; Owino, E. A. O.; Kubo, Y.; Inaba, A. Regulation of genes encoding ethylene biosynthesis enzymes in peach (Prunus persica L.) fruit by carbon dioxide and 1-methylcyclopropene. Postharvest Biol. Technol. 2001, 21, 265-281.

(6) Caprioli, I.; Lafuente, M. T.; Rodrigo, M. J.; Mencarelli, F. Influence of postharvest treatments on quality, carotenoids, and abscissic acid content of stored Spring Belle peach (Prunus persica) fruit. J. Agric. Food Chem. 2009, 57, 7056-7063.
(7) Ponce-Valadez, M.; Watkins, C. B. Fermentation and malate metabolism in response to elevated $\mathrm{CO}_{2}$ concentrations in two strawberry cultivars. Phvsiol. Plant. 2008, 134, 121-133.

(8) Yamada, M.; Taira, S.; Ohtsuki, Sato, A.; Iwanami, H.; Yakushiji, H.; Wang, R.; Yang, Y.; Li, G. Varietal differences in the ease of astringency removal by carbon dioxide gas and ethanol vapor treatments among oriental astringent persimmons of Japanese and Chinese origin. Sci. Hortic. 2002, 94, 63-72.

(9) Pesis, E.; Ben-Arie, R. Involvement of acetaldehyde and ethanol accumulation during induced deastringency of persimmon fruits. J. Food Sci. 2006, 49, 896-899.

(10) Rothan, C.; Duret, S.; Chevalier, C.; Raymond, P. Suppression of ripening-associated gene expression in tomato fruit subjected to a high $\mathrm{CO}_{2}$ concentration. Plant Phvsiol. 1997, 114, 255-263.

(11) Ponce-Valadez, M.; Fellman, S. M.; Giovannoni, J.; Gan, S. S.; Watkins, C. B. Differential expression in two strawberry cultivars in response to elevated $\mathrm{CO}_{2}$ during storage revealed by a heterologous fruit microarray approach. Postharvest Biol. Technol. 2009, 51, 131-140.

(12) Shin, Y.; Ryu, R. H.; Nock, J. F.; Polar-Cabrera, K.; Watkins, C. B. Fruit quality, antioxidant contents and activity and antiproliferative activity of strawberry fruit stored in elevated $\mathrm{CO}_{2}$ atmospheres. J. Food Sci. 2008, 73, S339-S344.

(13) Gil, M. I.; Holcroft, D. M.; Kader, A. A. Changes in strawberry anthocyanins and other polyphenols in response to carbon dioxide treatments. J. Agric. Food Chem. 1997, 45, 1662-1667.

(14) Sanchez-Ballesta, M. T.; Jimenez, J. B.; Romero, I.; Orea, J. M.; Maldonado, R.; Gonzales-Urena, A.; Escribano, M. I.; Merodio, C. Effects of high $\mathrm{CO}_{2}$ pretreatment on quality, fungal decay and molecular regulation of stilbene phytoalexin biosynthesis in stored table grapes. Postharvest Biol. Technol. 2006, 42, 209-216.

(15) Sanchez- Ballesta, M. T.; Romero, I.; Jimenez, J. B.; Orea, J. M.; Gonzales-Urena, A.; Escribano, M. I.; Merodio, C. Involvement of the phenylpropanoid pathway in the response of table grapes to low temperature and high $\mathrm{CO}_{2}$ levels. Postharvest Biol. Technol. 2007, 46, 29-35.

(16) Romero, I.; Sanchez-Ballesta, M. T.; Maldonado, R.; Escribano, M. I.; Merodio, C. Anthocyanin, antioxidant activity and stressinduced gene expression in high $\mathrm{CO}_{2}$-treated table grapes stored at low temperature. J. Plant Phvsiol. 2008, 165, 522-530.

(17) Versari, A.; Parpinello, G. P.; Tornielli, G. B.; Ferrarini, R.; Giulivo, C. Stilbene compounds and stilbene synthase expression during ripening, wilting and UV treatment in grape cv. Corvina. J. Agric. Food Chem. 2001, 49, 5531-5536.

(18) Bellincontro, A.; De Santis, D.; Botondi, R.; Villa, I.; Mencarelli, F. Different postharvest dehydration rates affect quality characteristics and volatile compounds of Malvasia, Trebbiano and Sangiovese grapes for wine production. J. Sci. Food Agric. 2004, 84, 1791-1800.

(19) Chkaiban, L.; Botondi, R.; Bellincontro, A.; De Santis, D.; Kefalas, P.; Mencarelli, F. Influence of postharvest water stress on lipoxygenase and alcohol dehydrogenase activities, and on the composition of some volatile compounds of Gewürztraminer grapes dehydrated under controlled and uncontrolled thermohygrometric conditions. Aust. J. Grape Wine Res. 2007, 13, 142-149.

(20) Bellincontro, A.; Fardelli, A.; De Santis, D.; Botondi, R.; Mencarelli, F. Postharvest ethylene and 1-MCP treatments both affect phenols, anthocyanins, and aromatic quality of Aleatico grapes and wine. Aust. J. Grape Wine Res. 2006, 12, 141-149.

(21) Zamboni, A.; Minoia, L.; Ferrarini, A.; Tornielli, G. B.; Zago, E.; Delledonne, M.; Pezzotti, M. Molecular analysis of post-harvest withering in grape by AFLP transcriptional profiling. J. Exp. Bot. 2008, 59 (15), 4145-4159.

(22) Rizzini, F. M.; Bonghi, C.; Tonutti, P. Postharvest water loss induces marked changes of transcript profiling in skins of wine grape berries. Postharvest Biol. Technol. 2009, 52, 247-253.

(23) Barbolan, A. M. A.; Zorro, L.; Guillen, D. A.; Barroso, C. G. Study of the polyphenol content of red and white grape varieties by liquid chromatography-mass spectrometry and its relationship to antioxidant power. J. Chromatogr., A 2003, 1012, 31-38.

(24) Kim, D.-O.; Chun, O. K.; Kim, Y. J.; Moon, H.-Y.; Lee, C. Y. Quantification of polyphenolics and their antioxidant capacity in fresh plums. J. Agric. Food Chem. 2003, 51, 6509-6515. 
(25) Romani, A.; Mancini, P.; Tatti, S.; Vincieri, F. F. Polyphenols and polysaccharides in Tuscan grapes and wines. Ital. J. Food Sci. 1996, $1,13-24$.

(26) Nigel, C. W.; Glories, Y. Use of a modified dimethylaminocinnamaldehyde reagent for analysis of flavanols. Am. J. Enol. Vitic. 1991, 42, 364-366.

(27) Waterman, P. G.; Mole, S. Analysis of phenolic plant metabolites. In Methods in Ecology; Blackwell Scientific Publications: Oxford, U.K., 1994.

(28) Sun, B.; Leandro, C.; da Silva, J. M. R.; Spranger, I. Separation of grape and wine proanthocyanidins according to their degree of polymerization. J. Agric. Food Chem. 1998, 46, 1390-1396.

(29) Gonzàlez-Manzano, S.; Rivas-Gonzalo, J. C.; Santuos-Buelga, C. Extraction of flavan-3-ols from grape seed and skin into wine using simulated maceration. Anal. Chim. Acta 2004, 513, 283-289.

(30) Da Silva, F. G.; Iandolino, A.; Al-Kayal, F.; Al-Kayal, F.; Bohlmann, M. C.; Cushman, M. A.; Lim, H.; Ergul, A.; Figueroa, R.; Kabuloglu, E. K.; Osborne, C.; Rowe, J.; Tattersall, E.; Leslie, A.; Xu, J.; Baek, J.; Cramer, G. R.; Cushman, J. C.; Cook, D. R. Characterizing the grape transcriptome. Analysis of expressed sequence tags from multiple Vitis species and development of a compendium of gene expression during berry development. Plant Phvsiol. 2005, 139, 574-597.

(31) Trainotti, L.; Bonghi, C.; Ziliotto, F.; Zanin, D.; Rasori, A.; Casadoro, G.; Ramina, A.; Tonutti, P. The use of microarray $\mu \mathrm{PEACH} 1.0$ to investigate transcriptome changes during transition from pre-climacteric to climacteric phase in peach fruit. $\underline{\text { Plant } S c i}$. 2006, 170, 606-613.

(32) Ziliotto, F.; Begheldo, M.; Rasori, A.; Bonghi, C.; Tonutti, P. Transcriptome profiling of ripening nectarine (Prunus persica $\mathrm{L}$. Batsch) fruit treated with 1-MCP. J. Exp. Bot. 2008, 59, 2781-2791.

(33) Tusher, V. G.; Tibshirani, R.; Chu, G. Significance analysis of microarrays applied to the ionizing radiation response. Proc. Natl. Acad.Sci.U.S.A. 2001, 98, 5116-5121.

(34) Rotter, A.; Camps, C.; Lohse, M.; Kappel, C.; Pilati, S.; Hren, M.; Stitt, M.; Coutos-Thévenot, P.; Moser, C.; Usadel, B.; Delrot, S.; Gruden, K. Gene expression profiling in susceptible interaction of grapevine with its fungal pathogen Eutypa lata: extending MapMan ontology for grapevine. BMC Plant Biol. 2009, 9, 104.

(35) Grimplet, J.; Deluc, L. G.; Tillett, R. L.; Wheatley, M. D.; Schlauch, K. A.; Cramer, G. R.; Cushman, J. C. Tissue-specific mRNA expression profiling in grape berry tissues. BMC Genomics 2007, $8,187$.
(36) McClellan, C. A.; Chang, C. The role of protein turnover in ethylene biosynthesis and response. Plant Sci. 2008, 175, 24-31.

(37) Wheeler, S.; Loveys, B.; Ford, C.; Davies, C. The relationship between the expression of abscisic acid biosynthesis genes, accumulation of abscisic acid and the promotion of Vitis vinifera L. berry ripening by abscisic acid. Aust. J. Grape Wine Res. 2009, 15, 195-204.

(38) Cutler, A.; Krochko, J. E. Formation and breakdown of ABA. Trends Plant Sci. 1999, 4, 472-478.

(39) Cabanne, C.; Doneche, B. Changes in polygalacturonase activity and calcium content during ripening of grape berries. Am. J. Enol. Vitic. 2001, 52, 331-335.

(40) Deytieux-Belleau, C.; Vallet, A.; Doneche, B.; Geny, L. Pectin methylesterase and polygalacturonase in the developing grape skin. Plant Phvsiol. Biochem. 2008, 46, 638-646.

(41) Holcroft, D. M.; Gil, M. I.; Kader, A. A. Effect of carbon dioxide on anthocyanins, phenylalanine ammonia lyase and glucosyltransferase in the arils of stored pomegranates. J. Am. Soc. Hortic. Sci. 1998, 123, 136-140.

(42) Deng, Y.; Wu, Y.; Li, Y. F. Physiological responses and quality attributes of Kyoho grapes to controlled atmosphere storage. LWT-Food Sci. Technol. 2006, 39, 584-590.

(43) Adams, D. O. Phenolics and ripening in grape berries. Am. J. Enol. Vitic. 2006, 57, 249-256.

(44) Takos, A. M.; Ubi, B. E.; Robinson, S. P.; Walker, A. R. Condensed tannins biosynthesis genes are regulated separately from other flavonoid biosynthesis genes in apple fruit skin. Plant Sci. 2006, 170, 487-499.

(45) Veluri, R.; Weir, T. L.; Bais, H. P.; Termitz, F. R. S.; Ivanco, J. M. V. Phytotoxic and antimicrobial acrtivities of catechin derivatives. J. Agric. Food Chem. 2004, 52, 1077-1082.

(46) Terry, L. A.; Crisosto, C. H.; Forney, C. F. Small fruit and berries. In Modified and Controlled Atmosphere for the Storage, Transportation, and Packaging of Horticultural Commodities; Yahia, E. M., Ed.; CRC Press: Boca Raton, FL, 20091 pp 363-395.

(47) Battilani, P.; Pietri, A. Ochratoxin, A in grapes and wine. Eur. J. Plant Pathol. 2002, 108, 639-643.

(48) Magan, N.; Aldred, D. Postharvest control strategies: minimizing mycotoxins in the food chain. Int. J. Food Microbiol. 2007, 119, 131-139.

Received for review March 11, 2010. Revised manuscript received June 3, 2010. Accepted June 4, 2010. This work has been financially supported by the Fondazione Cassa di Risparmio di Pisa. 